\title{
COST Actions G1 and G8: EU programs on the use of radiation in art and archaeometry
}

\author{
Annemie Adriaens ${ }^{\mathrm{a}, *}$, Guy Demortier ${ }^{\mathrm{b}}$ \\ ${ }^{a}$ Department of Analytical Chemistry, Ghent University, Krijgslaan 281-S12, B-9000 Ghent, Belgium \\ ${ }^{\mathrm{b}}$ Facultés Universitaires Notre-Dame de la Paix, LARN, 61 rue de Bruxelles, B-5000 Namur, Belgium
}

Received 21 October 2003; received in revised form 6 May 2004

\begin{abstract}
This paper gives an overview of the research activities within the European COST Actions G1 and G8. Both actions aim at achieving a better preservation and conservation of our cultural heritage by increasing the knowledge in art and archaeological objects through chemical and physical analyses.
\end{abstract}

(C) 2004 Elsevier B.V. All rights reserved.

PACS: 81; 82.80.-d

Keywords: Cultural heritage; COST Actions; Analytical techniques; Non-destructive analysis; IBA

\section{Introduction}

Europe has a particularly rich and diversified cultural heritage, including buildings, monuments and objects of all sizes, comprised of a great variety of materials. It defines our cultural foreground, directly influencing the environment in which we live. Moreover it provides the motivation for cultural tourism, and is the basis for a rich diversity of learning.

Much of this heritage is seriously endangered through a variety of factors and influences, such as pollution, ageing, natural disasters, essential tourist

\footnotetext{
${ }^{*}$ Corresponding author. Tel.: +32-9-264-4826; fax: +32-9264-4960.

E-mail address: annemie.adriaens@ugent.be (A. Adriaens).
}

access, ignorance or simple negligence. As a result it urgently needs to be properly protected and preserved for the benefit of both current and future generations. Frequently, the conservation measures required are underdeveloped, not well understood or widely known. As the complexity of the problem becomes both more evident and greater through the application of modern scientific techniques, the proposed solutions and the means of investigating them become also increasingly sophisticated. Unless conservation measures are urgently researched, disseminated and applied to the preservation of this "fragile and non-renewable resource", it is clear that "... there will be nothing left to provide access to or to educate people about" [1].

Whilst there is general agreement that action is required to halt or mitigate decline, few people know that high level research and technology play 
an essential role in protecting Europe's cultural heritage. The application of analytical techniques - initially developed in and for the field of materials science - to art or archaeological objects gives the historian and the archaeologist quantitative information which helps them understand the way of life in the cultures they are studying or the technical and intellectual know-how of the artists or craftsmen of the period under consideration. In museums, this knowledge is also necessary for the conservation and restoration of objects, or to assess the authenticity of artefacts and paintings proposed for acquisition. Moreover degradation phenomena must be studied to understand their cause, their kinetics and to find out ways of preventing or slowing them down.

The intergovernmental framework for European cooperation in the field of scientific and technical research (COST) supports, amongst other initiatives, actions that coordinate the use of analytical techniques in cultural heritage research [2]. COST is an EU initiative that allows the coordination of nationally funded research at a pan-European level and its activities are based on so-called actions which are networks on a specific topic covering basic and pre-competitive research. Today COST has almost 200 actions running, involving 34 member countries and participating institutions from nine non-member countries. In what follows an overview will be given on the activities of two COST Actions G1 and G8.

\section{COST Action G1}

Action G1 "Application of Ion Beam Analysis to Art or Archaeological Objects" - launched in 1995 - was the first COST Action specifically devoted to cultural heritage research. The action ran for 5 years and involved the participation of 12 member countries. Table 1 lists the participating research laboratories (20 in total) together with their infrastructure. Seven of those laboratories did not have their own IBA infrastructure at the time, but were invited to join other teams in order to solve specific problems.

The most popular ion beam analysis (IBA) technique is particle induced $\mathrm{X}$-ray emission
(PIXE). In cultural heritage studies PIXE analyses are usually performed in a non-vacuum geometry with or without a helium atmosphere around the specimen under investigation, depending on the $\mathrm{X}$-ray signal to be detected. Non-vacuum geometry is ideal for the study of fragile materials (such as manuscripts), large objects (statues, paintings) and for a rapid choice of regions to be analysed (inclusions in potteries and metals, details on paint layers, solders on gold artefacts). As a result an external beam facility is installed in nearly all laboratories using IBA techniques for archaeological purposes. Most of this infrastructure is located at research institutes. The Louvre Museum (Paris), however, had the AGLAE laboratory (Accelerator Grand Louvre pour l'Analyse Elémentaire) installed at the end of the 1980s and forms an exception in this respect. Its main goal is to provide, within the museum, analytical means and expertise to a large group of historians and archaeologists. The research teams of Florence, Namur, Orléans, Athens and Oxford have been involved in the field for a longer time. Contacts also exist with experts outside Europe such as at Delaware (USA), Lower-Hutt (New Zealand), Faure (South Africa) and Lucas Heights (Australia) [3]. Apart from PIXE other IBA methods are being used in the field as well. The Paris group, in collaboration with the Debrecen staff, for instance have developed an external beam of deuterons to perform simultaneously PIXE analysis of medium and heavy elements and particle induced gamma ray emission (PIGE) studies of light elements. The Florence and Paris groups frequently use Rutherford backscattering spectroscopy (RBS) in a nonvacuum geometry, while the teams of Oxford and Namur perform their microprobe studies by using PIXE and RBS signals simultaneously [3-5].

\subsection{Objectives and benefits of COST Action G1}

COST Action G1 has pursued three main objectives:

(a) The development of non-destructive analysis methods for the study of art and archaeological objects using particle irradiation. One of the major difficulties researchers encounter is 
Table 1

List of participating laboratories in COST Action G1

Participating laboratories 
to convince curators of museums that very energetic beams may be applied in a way not to induce damage in precious materials. The large cross section for PIXE and RBS and the large efficiency of solid state detectors for $\mathrm{X}$-ray and particle detection allow us to use very low intensity beams: $0.1 \mathrm{nA}$ for a few minutes is generally sufficient to obtain concentrations with a satisfactory statistical accuracy. During a workshop held in Namur in February 1997, various irradiation facilities were tested in order to check the damage in test specimens. The incident beam was kept at a level of one order of magnitude higher than the one generally accepted for analysis. Various kinds of archaeological material were irradiated to check the potential surface alteration. Results showed that no trace of damage was visible except for paper documents. The team of Florence has a good experience in this field and could give information regarding that particular problem. The teams of Dresden, Paris, Florence, Liège and Helsinki have also performed non destructive examinations of paintings in order to identify successive layers on test materials by IBA methods and the team of Vienna using XRF [6].

(b) The comparison of these novel techniques with conventional investigation methods of objects of art already used in laboratories of museums. IBA methods are indeed very quantitative and reference samples for other methods can be certified this way [7].

(c) Set-up of an interdisciplinary forum of researchers involved in archaeology and archaeometry to initiate curators and historians to these novel technologies.

\subsection{Scientific programme of COST Action G1}

A total of six working groups were established, allowing close collaboration on specific topics that were either material oriented (paint layers, silicate materials, metals and organic materials), or involved the study of radiation damage (Table 2). The action coordinated its scientific activities among the participating groups by organising an exchange of samples and procedures. Also short-

Table 2

Overview of working groups in COST Action G1

\begin{tabular}{lll}
\hline Paint layers & Silicate materials & Metals \\
\hline Coordinator: & Coordinator: & Coordinator: \\
C. Neelmeijer, Dresden & M. Schreiner, Vienna & J. Barrandon, Orleans \\
Paintings: & Potteries: & Bronzes and Brass: \\
Budapest, Debrecen, Dresden & Antwerp, Athens, Bucharest, & Antwerp, Bucharest \\
Firenze, Helsinki, Le Louvre, Ljubljana, & Debrecen, Helsinki, Madrid, Namur, & Helsinki, Ljubljana, Madrid, Namur, \\
Namur, Orléans & Sevilla, Vienna & Orléans, Sevilla \\
Manuscripts: & Glass: & Silver: \\
$\begin{array}{l}\text { Dresden, Firenze, Le Louvre } \\
\text { Helsinki, Madrid, Orléans, Oxford }\end{array}$ & Bucharest, Debrecen, Dresden, & Helsinki, Ljubljana, Madrid, \\
& Le Louvre, Namur, Orléans, Vienna & Namur, Orléans, Oxford \\
& Flints: & Gold: \\
& Ljubljana, Le Louvre & Le Louvre, Madrid, Namur, Orléans, \\
& & Oxford, Sevilla \\
& Stones: & \\
\hline Organic materials & Antwerp, Le Louvre & \\
\hline Coordinator: & Conservation in Musea & Radiation damage \\
G. Grime, Oxford & Coordinator: & Coordinator: \\
Budapest, Debrecen, & J.-Cl. Dran, Paris & G. Demortier, Namur \\
Le Louvre, Orléans, Oxford & Antwerp, Le Louvre & Dresden, Le Louvre, Namur
\end{tabular}


Table 3

Collaboration topics within COST Action G1

\begin{tabular}{ll}
\hline Research topic & References \\
\hline $\begin{array}{l}\text { Development of inter-laboratory } \\
\text { standards for the analysis of paper }\end{array}$ & {$[10]$} \\
Characterization of paint layers & {$[6,11]$} \\
Provenance of obsidian artefacts & {$[12]$} \\
Chemical characterization of Iberic & {$[13,14]$} \\
$\quad$ and Celtiberic bronzes & \\
Technology of gold jewellery & {$[15-17]$} \\
Corrosion of glass objects & {$[18]$} \\
\hline
\end{tabular}

term scientific missions (STSM) were performed. Such missions gave specialists of different laboratories the opportunity to work together in one of the laboratories for a short period on artefacts of archaeological interest. On a regular basis workshops were organised in one of the laboratories, during which analytical research was performed on artefacts of archaeological interest provided by the participating laboratories. Priority was given to the study of artefacts recommended by archaeologists and historians who defined the archaeological pertinence of the analytical work. During the entire duration of the COST Action G1, 12 workshops and seminars were organised on general use of ion beam techniques for the study of archaeological artefacts (simulation of depth profiling analysis of pigments, problems of conservation in museums and on damage that could be made to fragile materials when using ion beam irradiation), including lectures on IBA techniques for archaeologists. Many curators are now convinced that the IBA techniques may give quantitative results in a non-destructive way.

The output of the COST Action G1 included ca 30 joint publications and two monographs $[8,9]$. Table 3 lists some of the collaborations.

\section{COST Action G8}

The success of COST Action G1 was motivating and a new action followed in 2001 - COST Action G8 "Non-destructive Analysis and Testing of Museum Objects" [19]. The end date of this action at the time of writing is August 2005. The action started off with five countries. In the mean time 21 countries have become member. Next to the 12 countries involved in COST Action G1 (Table 1) nine others have applied: Bulgaria, Czech Republic, Denmark, Israel, Malta, Netherlands, Poland, Slovakia and Switzerland.

\subsection{Objective and benefits of COST Action G8}

The main objective of COST Action G8 is to improve the preservation and conservation of our cultural heritage by increasing knowledge of museum objects through non-destructive analysis and testing. The use of additional non-destructive techniques (such as micro Raman, LIBS spectroscopy, video-thermography, photothermal deflection spectroscopy and Chemiluminescence) and the expansion to a multidisciplinary community allows us to obtain further complementary information.

There is an increasing need for non-destructive investigations, as sampling is in most cases restricted in view of the value or the uniqueness of the object. Even in cases that allow sampling, nondestructive testing offers the possibility of obtaining more information about one specific sample as complementary techniques may be applied. In the analytical sciences many non-destructive techniques are available, such as ion beam analysis, autoradiography and optical spectroscopy, all of which can, in principle, be used in this field. Museums, however, do not always have access to these techniques, while many of the necessary research instruments and analytical facilities are located in specialised research institutes, as they require very specific expertise. Some techniques may still need to be introduced and established in the field of cultural heritage.

The action aims at creating a Europe-wide environment, in which people directly concerned with the maintenance of our cultural heritage (i.e. art historians, archaeologists, conservators and curators) and analytical scientists (i.e. physicists, chemists, material scientists, geologists, etc.) can exchange knowledge. A $50 / 50 \%$ balance is aimed at between the activities of both groups, which should result in greater interest. The expected benefits are twofold. First, the capability of answering questions related to museum objects, which cannot be readily solved now, will be 
enhanced. This includes the exchange of knowledge of available non-destructive techniques and the requirements for performing investigations on valuable or unique objects. In addition, museums and similar institutes will have easy access to universities and research facilities that provide such techniques.

\subsection{The scientific programme of COST Action G8}

Similar as in Action G1, COST Action G8 has three main scientific activities. The first one includes organising short-term scientific missions between participating institutions. The goal of these STSM (5 days-1 month) involves the training of scientists of both professional groups in the other's field as well as the transfer of practical experience among European countries. Priority here is especially given to young researchers. Secondly, regular meetings in the form of workshops are organised, often in collaboration with museums and conservation institutes, to exchange obtained knowledge in a broader group, to discuss new themes, and to build interest and create possibilities for new collaborations [20]. The goals of both activities are summarized in detail in Table 4 .

Apart from to the yearly workshops and STSM between participating groups, separate working groups have been created. The working groups allow a close collaboration and an extended and efficient exchange of knowledge within a specific topic, and therefore a more efficient way of publishing the obtained results. The following themes are addressed [19]:
- Technology and authenticity, involving the identification of the materials and their production techniques. Within this working group two distinct but related topics are studied: (1) the investigation and verification of ancient recipes starting from the Mesopotamian and Egyptian texts up to the 19th century books of technology descriptions about how craftsmen prepared and made their products are available and (2) the authentication of art and archaeological objects, i.e. the identification of fakes.

- Origin and provenance, including the characterization and location of the natural sources of the raw materials used to make (museum) objects. The main goal is to contribute to establishing patterns of raw material procurement, trade or exchange.

- Degradation processes, corrosion, weathering. This working group deals with the problem of alteration of museum objects and the way non-destructive techniques can be used to measure this damage or monitor it with time.

- Preservation and conservation. The working group is concerned with the treatment of works of art in order to slow down deterioration, the identification of the nature and extent of damage, the assessment of the causes of deterioration. Work in this field also implies the control of the environment in which the object is located, such as monitoring of the temperature, relative humidity and lighting, ensuring proper storage, support and security.

- Development of analysis procedures involving three main goals: (1) the use and improvement

Table 4

Scientific goals of short-term scientific missions and workshops in COST Action G8

\begin{tabular}{ll}
\hline Short term scientific missions & Workshops \\
\hline Train scientists of both professional groups in the other's field as well as transfer & $\begin{array}{l}\text { Exchange (obtained) knowledge in a } \\
\text { broader group } \\
\text { practical experience between the European countries }\end{array}$ \\
$\begin{array}{l}\text { Address specific problems concerning museum objects as well as collect and compare } \\
\text { data }\end{array}$ & $\begin{array}{l}\text { of the techniques } \\
\text { Build interest and give the possibility } \\
\text { of new collaborations }\end{array}$ \\
Compare the use of standing facilities and portable equipment & $\begin{array}{l}\text { Assist in choosing the method(s) best } \\
\text { suited for a specific problem }\end{array}$ \\
Exploit the advantages and limitations of the different techniques also in comparison \\
to techniques commonly used today in the field of cultural heritage \\
Art historians, archaeologists and conservators obtain easier access to analytical \\
research instruments
\end{tabular}


of truly non-destructive techniques (they do not require a sample to be removed from the object), (2) the maximization of information and minimization of consumed volume where a sample must be removed and (3) the development of portable/mobile equipment so monitoring can be done on site.

- Biological and Material Culture of Qumran at the Dead Sea. This working group deals with three aspects of the study of material remains at Qumran, i.e. the biological and the material cultural ones and the conservation of this cultural heritage.

\section{Concluding remarks}

For all these research activities it is important to emphasize that the multidisciplinary community of action is essential. In the current economic climate it is extremely difficult for museums to develop new analytical methods or techniques. The need for collaboration with experts in state-of-theart analytical instrumentation is therefore very high and can tap-in to sources of knowledge and sophistication of equipment, which would otherwise be impossible in the small conservation and science groups in museums.

\section{Acknowledgements}

We thank the financial support of the European Communities for the financial support for the various short-term scientific missions with COST Actions G1 and G8 mainly attributed to young scientists and for allowing analytical experts to meet on a regular basis to discuss the progress of their common research.

\section{References}

[1] First report of the All-Party Parliamentary Archaeology Group (APPAG). The Current State of Archaeology in the
United Kingdom, The Caxton \& Holmesdale Press Ltd., Kent, 2003.

[2] http://cost.cordis.lu/src/whatiscost.cfm.

[3] P. Mandò, Nucl. Instr. and Meth. B 85 (1994) 81.

[4] R.A. Jarjis, Nucl. Instr. and Meth. B 118 (1996) 62.

[5] G. Demortier, J.L. Ruvalcaba, Nucl. Instr. and Meth. B 118 (1996) 352.

[6] C. Neelmeijer, I. Brissaud, T. Calligaro, G. Demortier, A. Hautojärvi, M. Mäder, L. Martinot, et al., X-ray Spectrom. 29 (2000) 101.

[7] C. Neelmeijer, J. Huller, M. Mader, B. Borchers, R. Jarjis, Nucl. Instr. and Meth. B 136-138 (1998) 902.

[8] M.A. Respaldiza, J. Gomez-Camacho (Eds.), Applications of Ion Beam Analysis Techniques to Arts and Archaeometry, Secretariado de Publicaciones de la Universidad de Sevilla, Sevilla, 1997.

[9] G. Demortier, A. Adriaens (Eds.), Ion Beam Study of Art and Archaeological Objects, EUR 19218, Office for Official Publications of th European Commision, Luxembourg, 2000.

[10] R.A. Jarjis, in: Y. Ibish (Ed.), Conservation and Preservation of Islamic Manuscripts, Al-Furqan Publication, London, 2000.

[11] C. Neelmeijer, W. Wagner, M.P. Schramm, Nucl. Instr. and Meth. B 118 (1996) 338.

[12] I. Borbely-Kiss, T. Gessztelyi, Z. Elekes, I. Rajta, E. Kotaly, A.Z. Kiss, Investigation of classical ring-stones and their imitations, in: Proc. Fifth Int. Conf. Nondestructive Testing (Art'96), 24-26 September 1996, Budapest, Hungary, 131.

[13] A. Climent-Font, G. Demortier, C. Palaccio, I. Montero, J.L. Ruvalcaba, D. Diaz, Nucl. Instr. and Meth. B 134 (1998) 229.

[14] L. Martinot, G. Demortier, J. Guillaume, A. Chevalier, P. Colman, Dinanderies Médiévales, Feuillets de la Cathédrale de Liège, No. 27, 1996.

[15] J.-L. Ruvalcaba-Sil, G. Demortier, Nucl. Instr. and Meth. B 130 (1997) 297.

[16] M.A. Ontalba-Salamanca, G. Demortier, F. FernandezGomez, P. Coquay, J.L. Ruvalcaba-Sil, M.A. Respaldiza, Nucl. Instr. and Meth. B 136-138 (1998) 851.

[17] G. Demortier, F. Fernandez-Gomez, M.A. Ontalba-Salamanca, P. Coquay, Nucl. Instr. and Meth. B 158 (1999) 275.

[18] M. Mader, D. Grambole, F. Merrmann, C. Neelmeijer, M. Schreiner, G. Woisetschlager, Nucl. Instr. and Meth. B 136-138 (1998) 863.

[19] http://srs.dl.ac.uk/arch/cost-g8.

[20] J. Townsend, K. Eremin, A. Adriaens (Eds.), Conservation Science 2002, Archetype Publications, London, 2003. 